\title{
Generation of a Chinese Hamster Ovary Cell Line Producing Recombinant Human Glucocerebrosidase
}

\author{
Juliana Branco Novo, ${ }^{1,2}$ Ligia Morganti, ${ }^{3}$ Ana Maria Moro, ${ }^{4}$ Adriana Franco Paes Leme, ${ }^{5}$ \\ Solange Maria de Toledo Serrano, ${ }^{5}$ Isaias Raw, ${ }^{1}$ and Paulo Lee Ho ${ }^{1,2}$ \\ ${ }^{1}$ Centro de Biotecnologia, Instituto Butantan, Avenue Vital Brasil, 1500, 05503-900 São Paulo, SP, Brazil \\ ${ }^{2}$ Interunidades em Biotecnologia, Instituto de Ciências Biomédicas, Universidade de São Paulo, 05508-000 São Paulo, SP, Brazil \\ ${ }^{3}$ Centro de Biotecnologia, Instituto de Pesquisas Energéticas e Nucleares, 055508-000 São Paulo, SP, Brazil \\ ${ }^{4}$ Laboratório de Biofármacos em Células Animais, Instituto Butantan, Avenue Vital Brasil, 1500, 05503-900 São Paulo, SP, Brazil \\ ${ }^{5}$ Laboratório Especial de Toxinologia Aplicada, CAT-cepid, Instituto Butantan, Avenue Vital Brasil, 1500, \\ 05503-900 São Paulo, SP, Brazil
}

Correspondence should be addressed to Paulo Lee Ho, hoplee@butantan.gov.br

Received 9 March 2012; Revised 30 June 2012; Accepted 19 July 2012

Academic Editor: D. M. Clarke

Copyright ( $) 2012$ Juliana Branco Novo et al. This is an open access article distributed under the Creative Commons Attribution License, which permits unrestricted use, distribution, and reproduction in any medium, provided the original work is properly cited.

Impaired activity of the lysosomal enzyme glucocerebrosidase (GCR) results in the inherited metabolic disorder known as Gaucher disease. Current treatment consists of enzyme replacement therapy by administration of exogenous GCR. Although effective, it is exceptionally expensive, and patients worldwide have a limited access to this medicine. In Brazil, the public healthcare system provides the drug free of charge for all Gaucher's patients, which reaches the order of $\$ 84$ million per year. However, the production of GCR by public institutions in Brazil would reduce significantly the therapy costs. Here, we describe a robust protocol for the

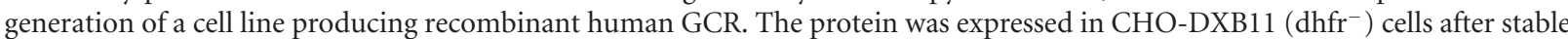
transfection and gene amplification with methotrexate. As expected, glycosylated GCR was detected by immunoblotting assay both as cell-associated $(\sim 64$ and $59 \mathrm{kDa})$ and secreted $(63-69 \mathrm{kDa})$ form. Analysis of subclones allowed the selection of stable $\mathrm{CHO}$ cells producing a secreted functional enzyme, with a calculated productivity of $5.14 \mathrm{pg} / \mathrm{cell} / \mathrm{day}$ for the highest producer. Although being laborious, traditional methods of screening high-producing recombinant cells may represent a valuable alternative to generate expensive biopharmaceuticals in countries with limited resources.

\section{Introduction}

Glucocerebrosidase (GCR; EC 3.2.1.45) is a membraneassociated lysosomal enzyme [1] responsible for the hydrolysis of glucocerebroside to glucose and ceramide $[2,3]$. Deficiency in the GCR activity results in Gaucher disease, the most common lysosomal storage disorder [4] characterized by an accumulation of the glycolipid in the monocytemacrophage system $[5,6]$, mainly in liver, spleen and bone marrow. Gaucher disease is an autosomal recessive disorder [7], caused by more than 300 mutations in the GCR gene $[5,8]$, which results in a highly variable clinical presentation. According to the symptoms, Gaucher disease is historically classified into types I, II, and III $[4,6]$.
Type I (nonneuronopathic) is the most prevalent form [9], usually treated by enzyme replacement therapy (ERT) [10] via intravenous infusions of recombinant GCR produced in Chinese hamster ovary $(\mathrm{CHO})$ cells [11]. ERT has proven to be safe and effective [8], reversing most symptoms of the disease in more than 4,500 patients worldwide [12]. This therapy was first introduced in 1991, using human placentalderived GCR (aglucerase, Ceredase) that was then replaced in 1994 by the recombinant form (imiglucerase, Cerezyme) $[5,12,13]$, both manufactured by Genzyme Corporation (Cambridge, MA, USA), which was latterly acquired by Sanofi-Aventis (Montpellier, France). Currently, two new recombinant GCRs, regarded as biosimilar (or follow-on) preparations of imiglucerase [14], have received market 
approval $[15,16]$ : a gene-activated GCR (velaglucerase alfa, VPRIV, Shire Human Genetic Therapies, Cambridge, MA, USA) produced in a human fibroblast cell line [1719] and a plant-derived human GCR (taliglucerase alfa, Elelyso, Protalix Biotherapeutics, Carmiel, Israel) [20, 21]. Recently, a viral contamination occurred in the Genzyme's bioreactor resulting in a global supply shortage of Cerezyme. As a consequence, both enzymes velaglucerase alfa and taliglucerase alfa had an accelerated market entry [22]. There is a great expectation that these and possibly other GCR formulations emerging in the near future could lead to a reduction in the price of the drug, which is extremely expensive [8] and hampers access to treatment [2, 14], especially in countries with limited resources [23-25]. Here, we propose the cloning and expression of human GCR in $\mathrm{CHO}$ cells, in order to obtain high-expressing clones suitable for future GCR production at a lower cost by Institute Butantan (São Paulo, Brazil). The Institute Butantan has the public mission of producing sera, vaccines, and biopharmaceuticals at reduced costs for the Brazilian public healthcare system. The GCR cDNA was inserted into the pED dicistronic expression vector [26], and the recombinant protein was expressed in CHO-DXB11 cells, an auxotrophic line deficient in dihydrofolate reductase (DHFR) activity [27]. This is a well-characterized expression system [28, 29], commonly used in the biopharmaceutical industry for the production of glycoproteins $[30,31]$. Cells were submitted to gene amplification with increasing methotrexate (MTX), a competitive inhibitor of DHFR, and clones were selected by traditional methods to screen high producers since current high-throughput techniques are not available to most undeveloped or emerging countries. The properly glycosylated GCR was detected in the culture supernatants and cellular extracts. Subcloning of the best producer clone followed by long-term culture in the MTX-free medium allowed the selection of stable $\mathrm{CHO}$ cell lines producing a functional enzyme. In addition to a successful protocol for the generation of stable cells producing recombinant human GCR, this study shows that traditional screening methods to search for high-producing cell lines for recombinant proteins can be a useful alternative for the production of biopharmaceuticals in emerging countries.

\section{Materials and Methods}

2.1. Recombinant DNA Procedures. Human GCR cDNA was obtained by purification of total RNA from ECV 304 cells (ATCC CRL 1998), followed by cDNA synthesis through RT-PCR (results not shown). The 1,565 bp cDNA encoding human GCR with its own signal peptide was amplified by PCR using the forward primer $\left(5^{\prime}\right.$ TCT AGA CCA TGG CTG GCA GCC TCA CA $3^{\prime}$ ) containing a XbaI restriction site and the Kozak sequence (sequence in bold), and the reverse primer ( $5^{\prime}$ GAA TTC TCA CTG GCG ATG CCA CAG $3^{\prime}$ ) containing an EcoRI restriction site. PCR was performed using Pfx DNA polymerase (Invitrogen), $0.2 \mathrm{mM}$ of each deoxynucleoside triphosphate and $20 \mathrm{pmol}$ of each primer. PCR amplification conditions were as follows: $94^{\circ} \mathrm{C}$,
5 min; 30 cycles of $94^{\circ} \mathrm{C}, 1 \mathrm{~min} ; 52^{\circ} \mathrm{C}, 45 \mathrm{~s} ; 68^{\circ} \mathrm{C}, 3 \mathrm{~min}$; a single step of $68^{\circ} \mathrm{C}, 7 \mathrm{~min}$ for final extension. PCR products were cloned into the pGEM-T vector (Promega). DH5 $\alpha$ E. coli competent cells were transformed with the ligation product for propagation and amplification of the recombinant DNA. Positive clones were confirmed by DNA sequencing using an automated DNA sequencer (ABI 3100) based on the dideoxytermination method [32]. The GCR cDNA was mutated to produce an enzyme with His in place of Arg at position 495 (procedures not shown) (Figure 1). The resulted plasmid pGEM-T-GCR was digested and the insert was subcloned into the XbaI and EcoRI sites of the pED expression vector [26], kindly provided by Dr. R. J. Kaufman (Howard Hughes Medical Institute, University of Michigan Medical Center), which provides high-expression levels of heterologous proteins in mammalian cells based on a dicistronic expression system. The $\mathrm{pED}$ vector carriers the encephalomyocarditis virus leader sequence, a putative internal ribossomal entry site, inserted upstream of the selectable and amplifiable gene marker dhfr (Figure 1).

2.2. Cell Culture, Stable Transfection and Gene Amplification. Cells of the lineage CHO-DXB11 ( $\left.\mathrm{dhfr}^{-}\right)$[27] kindly provided by Dr. L. A. Chasin (Department of Biological Sciences, Columbia University), were maintained in Minimum Essential Medium Alfa Medium ( $\alpha$-MEM; Invitrogen) supplemented with $2 \mathrm{mM} \mathrm{L}$-glutamine, antibiotics (100 U/mL penicillin, $100 \mu \mathrm{g} / \mathrm{mL}$ streptomycin, $0.25 \mu \mathrm{g} / \mathrm{mL}$ amphotericin B; Invitrogen) and 10\% fetal bovine serum (FBS; Cultilab) (nonselective medium). Transfection of the plasmid pED-GCR $(20 \mu \mathrm{g})$ was carried out in $100 \mathrm{~mm}$ tissue culture plates containing $10^{6}$ cells by the calcium phosphate precipitation method [33]. The medium was replaced $48 \mathrm{~h}$ after transfection by $\alpha$-MEM without nucleosides and supplemented with 10\% dialyzed FBS (Invitrogen), antibiotics and L-glutamine (selective medium). After 2 weeks, 48 DHFR-positive clones (named as C 1 to C 48) were transferred into 12-well tissue culture plates using plastic inoculating loops and submitted to gene amplification with increasing MTX (Sigma) in the selective medium at concentrations of $0,20,50,150,350,700$, and $1200 \mathrm{nM}$. Cells were fed with fresh medium every 2-3 days and were passaged upon reaching confluence by trypsinization. In each selection step, cells were cultivated for at least 15 days before the MTX concentration was increased. To generate conditioned media and cell lysates for GCR expression analysis, cell clones were seeded into 6-well tissue culture plates containing selective medium and MTX. When semiconfluence was reached, cells were washed 3 times with PBS and the culture medium was replaced by selective medium lacking FBS. After incubation for $24 \mathrm{~h}$, both the culture medium (conditioned medium) and the cells were collected, centrifuged at $300 \times \mathrm{g}$ for $10 \mathrm{~min}$, and stored at $-80^{\circ} \mathrm{C}$ until use. Cell concentration was determined for each well with a Neubauer hemocytometer. For some analyses, cell culture supernatants were precipitated with $10 \%(\mathrm{v} / \mathrm{v})$ trichloroacetic acid (TCA) and washed with cold acetone. 


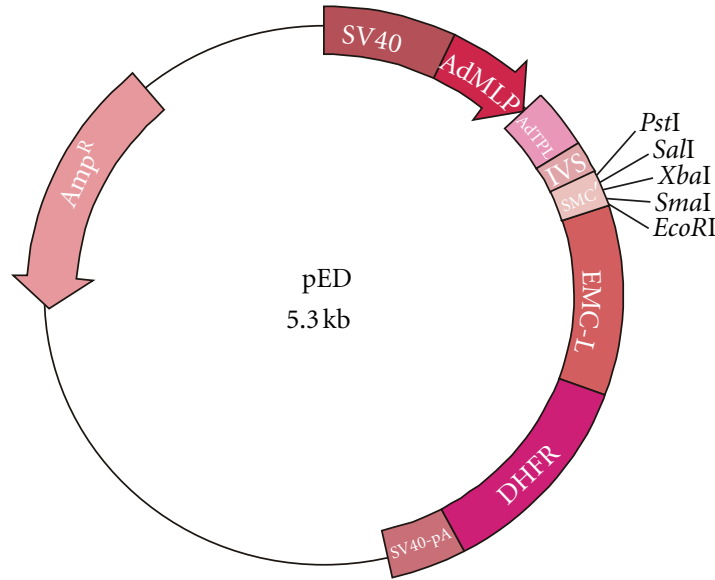

(a)

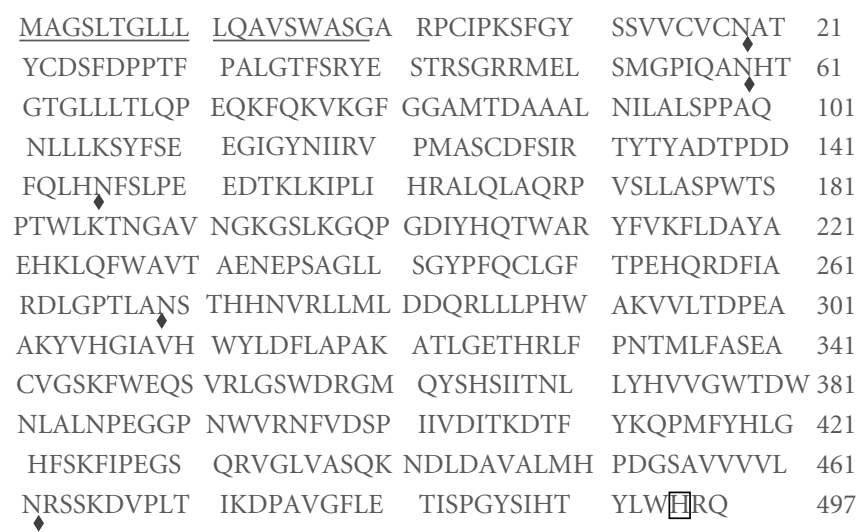

(b)

FIGURE 1: Strategy of cloning of GCR cDNA in the mammalian expression vector pED. (a) Map of dicistronic vector pED, a pUC 18 derivative, containing the simian virus 40 (SV40) origin of replication and enhancer element, the adenovirus major late promoter (AdMLP), the tripartite leader from adenovirus late mRNA (AdTPL), a hybrid intron composed of the $5^{\prime}$ splice site from the first leader of adenovirus major late mRNAs and a $3^{\prime}$ splice site from an immunoglobulin gene (IVS), a multiple cloning site (SMC), the $5^{\prime}$ untranslated leader from encephalomyocarditis (EMC-L) virus, a murine DHFR-coding region, the simian virus 40 late polyadenylation signal (SV40-pA), and ampicillin resistance gene for propagation and selection in E. coli $\left(\mathrm{Amp}^{\mathrm{R}}\right)$ [26]. GCR cDNA was cloned into XbaI and EcoRI sites. (b) Amino acid sequence of cloned GCR cDNA. The signal peptide of 19 amino acids is underlined. Potential carbohydrate binding asparagine residues are shown by diamonds. The arginine at position 495 was replaced by histidine (mutation R495H) (boxed).

All cell cultures were carried out at $37^{\circ} \mathrm{C}$ in a humidified incubator with $5 \% \mathrm{CO}_{2}$.

2.3. Single-Cell Subcloning Procedures. To isolate a cell line with the highest GCR productivity, cells from the best clone obtained at $700 \mathrm{nM}$ MTX were subcloned by seeding 50, 100 , and 200 cells into 3 separate $100 \mathrm{~mm}$ tissue culture plates and maintained in selective medium supplemented with MTX. After 15 days, 24 single-cell subclones (named as SC 12.1 to SC 12.24 ) were randomly selected, transferred to 12-well tissue-culture plates using plastic inoculating loops and expanded in the same medium for storage.

2.4. Clonal Stability Studies. The highest producer clone and the isolated subclones were cultured into 12-well tissue culture plates for 45 days in the absence of MTX selection pressure in nonselective medium. Cells were seeded into 6well tissue culture plates to obtain conditioned media, as previously described. Samples were collected on days 15, 30, and 45 of the culture, and analyzed for secreted GCR. Cell concentration was determined by counting each well after collection of the supernatant.

2.5. Western Blotting Analysis. CHO-DXB11 cell supernatants (conditioned media) in 1-fold SDS-PAGE sample buffer and $\mathrm{CHO}$ cell pellets lysed in 2-fold SDS-PAGE sample buffer, containing $8 \mathrm{M}$ urea, $1.5 \mathrm{mM}$ EDTA and a protease inhibitor cocktail (Sigma) were fractionated on a $10 \%$ SDS-PAGE and electrotransferred to nitrocellulose or PVDF membranes (GE Healthcare). The membranes were blocked with $5 \%(\mathrm{w} / \mathrm{v})$ nonfat dried milk in $0.1 \%(\mathrm{v} / \mathrm{v})$ Tween 20, $150 \mathrm{mM} \mathrm{NaCl}$, and $20 \mathrm{mM}$ Tris-HCl pH 8.0 (TBST) for $16 \mathrm{~h}$. Membranes were washed three times for $10 \mathrm{~min}$ with TBS-T, and further incubated with a $1: 4,000$ dilution of the murine anti-human GCR polyclonal antibodies [34], in $1 \%(\mathrm{w} / \mathrm{v})$ bovine serum albumin (BSA)/TBS-T, for $1.5 \mathrm{~h}$. The membranes were washed three times with TBS-T and incubated for $1 \mathrm{~h}$ with a proper dilution of anti-mouse IgG peroxidase conjugate (Sigma) in TBS-T, washed, and revealed with ECL or ECL Plus detection reagent (GE Healthcare), following manufacturer's instructions.

2.6. Enzymatic Activity Assay. Hydrolytic activity of secreted GCR was determined fluorometrically with synthetic substrate 4 -methylumbelliferyl- $\beta$-D-glucopyranoside (4-MUG; Sigma). The enzymatic reactions were performed in $0.2 \mathrm{~mL}$ of $0.2 \mathrm{M}$ citrate phosphate buffer $\mathrm{pH} 5.5$, containing $0.15 \%$ (v/v) Triton X-100 (Sigma), 0.125\% (w/v) sodium taurocholate (Sigma), $5 \mathrm{mM}$ 4-MUG, and conditioned media (collected as described above). After incubation for $1 \mathrm{~h}$ at $37^{\circ} \mathrm{C}$, the reactions were stopped by adding $1 \mathrm{~mL}$ of $0.1 \mathrm{M}$ glycine, $0.1 \mathrm{M} \mathrm{NaOH} \mathrm{pH} \mathrm{10.3.} \mathrm{The} \mathrm{product} \mathrm{of} \mathrm{enzymatic}$ reactions 4-methylumbelliferone (4-MU) was measured with a spectrometer SLM-AMINCO Bowman Series II (Spectronic Instruments) excitation wavelength $365 \mathrm{~nm}$, emission wavelength $445 \mathrm{~nm}$. A standard curve was constructed using well-known concentrations of commercial enzyme Cerezyme and specific activity data $(40 \mathrm{U} / \mathrm{mg})$ presented by the manufacturer. Total protein concentrations were determined by absorbance at $205 \mathrm{~nm}$ [35]. 
2.7. GCR Quantification. Quantification of recombinant human GCR secreted from CHO-DXB11 cell subclones was estimated by a standard curve containing well-known concentrations of nonglycosylated recombinant GCR purified from E. coli [34] on a 10\% SDS-PAGE, followed by western blotting and densitometry analysis. Conditioned media used for GCR quantification were collected as previously described. Densitometry analysis was performed using software from Eagle Eye still video system (Stratagene).

2.8. Endoglycosidase Digestion. Endo H and PNGase F digestion of recombinant GCR were performed in conditioned medium of the best producer subclone previously precipitated with $10 \%(\mathrm{v} / \mathrm{v})$ TCA and washed with cold acetone. Samples were heated for $10 \mathrm{~min}$ at $100^{\circ} \mathrm{C}$ in glycoprotein denaturing buffer, and reactions were performed according to the manufacturer's instructions (New England Biolabs). After incubation at $37^{\circ} \mathrm{C}$ for $16 \mathrm{~h}$, reaction products were subjected to $10 \%$ SDS-PAGE followed by western blotting analysis, as described above.

\section{Results}

3.1. GCR Expression in CHO-DXB11 Cells. The human GCR cDNA containing its signal peptide sequence (1,565 bp) and the mutation $\mathrm{R} 495 \mathrm{H}$ was cloned into the $\mathrm{pED}$ vector (Figure 1) for stable expression of GCR in CHO-DXB11 cells, with the aim of obtaining high-producing clones. Transfection efficiency using calcium phosphate was about $0,1 \%$. Transfected clones were treated with increasing MTX concentrations to amplify the copy number of integrated cDNA. After the third round of amplification with $150 \mathrm{nM}$ MTX, protein bands corresponding to glycosylated recombinant GCR were detected by western blotting analysis, using an anti-human GCR polyclonal antibody (Figure 2). Two to three GCR bands of $63-69 \mathrm{kDa}$ were observed in the conditioned media (Figure 2(a)), while bands around 64 and $59 \mathrm{kDa}$ were detected in cell lysates (Figure 2(b)). A $56 \mathrm{kDa}$ band was detected (Figures 2(a) and 2(b)) corresponding to nonglycosylated recombinant GCR purified from E. coli [34] (positive control).

The amplification process was followed using increasing concentrations of MTX up to $700 \mathrm{nM}$ in the culture medium. Utilization of MTX at higher concentration (1200 nM) was discontinued because it induced a high rate of cell death. At each increase step of MTX concentration, conditioned media were collected to evaluate the GCR expression by the cells. The western blotting analysis, performed with the anti-human GCR polyclonal antibody, showed that GCR expression levels were higher with increasing MTX concentration, which was evident in the last step with $700 \mathrm{nM}$ MTX in the culture medium (Figure 3). The nonglycosylated recombinant GCR of $56 \mathrm{kDa}$ purified from $E$. coli was used as positive control. These results suggested that $700 \mathrm{nM}$ was the highest concentration of MTX suitable for the amplification of the cDNA and consequently the generation of highproducer clones for GCR. With this purpose, clones selected at $700 \mathrm{nM}$ MTX were evaluated for GCR expression by western blotting analysis, and the clone 12 was chosen as the best expressing clone for GCR enzyme (data not shown).

3.2. Subcloning and Cell Culture in MTX-Free Medium. In order to evaluate the clonal stability for GCR expression, the high-producer clone (clone 12) was cultivated for 45 days in the absence of MTX selective pressure, and samples of conditioned medium were collected on days 15, 30, and 45. The western blotting assay showed a decreasing in the GCR expression over time (Figure 4(a)). After 45 days, the expression level of GCR by clone 12 was similar to that of nontransfected CHO-DXB11 cells (negative control), indicating absence of the recombinant protein expression. Since this analysis was carried out using a pool of cells, we hypothesized that most of the cells were unstable and only a few stably GCR expressing cells were present in the culture.

To identify stable high-producer cells from the amplified pool of cells derived from clone 12, a single-cell subcloning process was performed. The western blotting analysis of the conditioned culture medium of subclones cultivated for 45 days in the absence of MTX showed evident bands around $66 \mathrm{kDa}$ corresponding to recombinant GCR in 5 subclones analyzed (Figure 4(b)). The GCR expression level observed for these subclones was similar to that detected for the clone 12 maintained with $700 \mathrm{nM}$ MTX, and used as positive control. For 13 additional subclones analyzed in the absence of MTX, the GCR expression was not detected (data not shown).

3.3. Hydrolytic Activity of Recombinant GCR. The hydrolytic activity of secreted recombinant GCR was evaluated using the synthetic substrate 4-MUG for the 5 stable producer subclones identified in the western blotting analysis (Figure $4(\mathrm{~b})$ ). The presence of a functional GCR was observed for all subclones analyzed (Figure 5). Specific activities were calculated based on a standard curve containing well-known units of Cerezyme. GCR produced by subclones showed similar specific activities to commercial enzyme, taking into account that the protein had not been purified from the culture medium. The highest activity for GCR was detected in subclone $12.9(28.54 \pm 2.75 \mu \mathrm{mol} 4-\mathrm{MU} / \mathrm{min} / \mathrm{mg})$.

3.4. GCR Expression Levels. Recombinant GCR secreted from the best $\mathrm{CHO}-\mathrm{DXB} 11$ cell subclones was quantified by western blotting and densitometry analysis, based on a standard curve of nonglycosylated recombinant GCR purified from E. coli. As observed in Table 1, subclone 12.9 showed the highest specific productivity of recombinant GCR (5.14 pg/cell/day), followed by subclones 12.19 and 12.8 (3.22 and $1.84 \mathrm{pg} /$ cell/day, resp.). These results are in agreement with the enzymatic activity assay that showed the same order of potency to hydrolyze the synthetic substrate 4-MUG by these subclones. The subclone 12.9 was then selected as the best producer of recombinant GCR in secreted form.

3.5. Glycosylation Analyses of Recombinant GCR. Recombinant GCR secreted from the highest producer subclone 


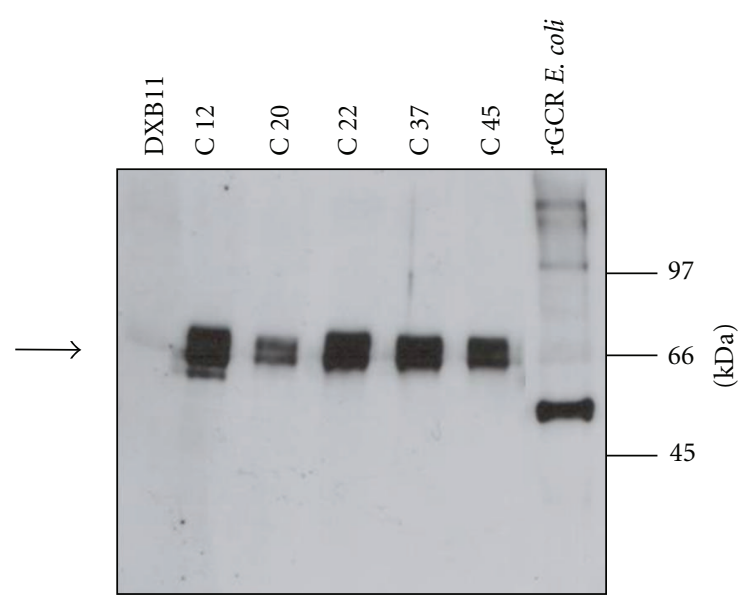

(a)

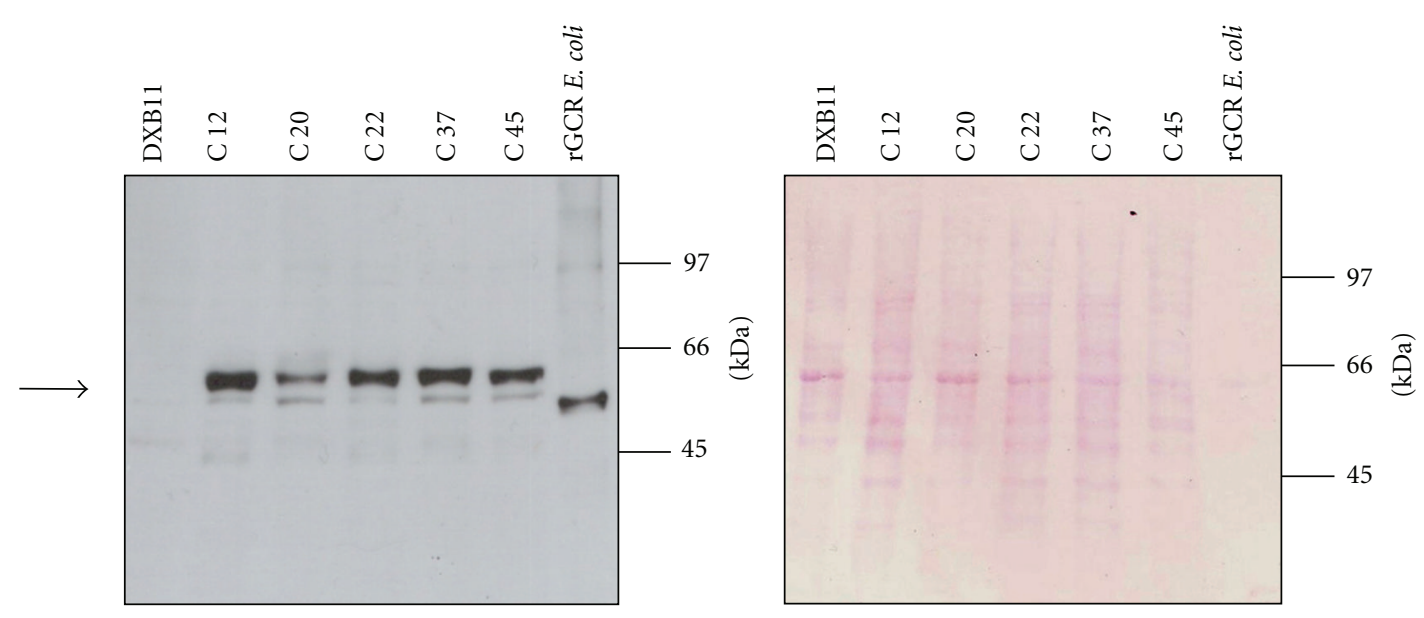

(b)

FIGURE 2: Western blotting analysis of the expression of recombinant human GCR in stably transfected CHO-DXB11 cells, after the third round of amplification with $150 \mathrm{nM}$ MTX. (a) Conditioned media of 5 selected clones (C 12, C 20, C 22, C 37, and C 45). (b) Cellular extracts from the selected clones and the corresponding membrane stained with Ponceau $\mathrm{S}$ after proteins transfer. The total protein from conditioned media was previously concentrated by precipitation with $10 \%$ TCA. Nonglycosylated recombinant human GCR of $56 \mathrm{kDa}$ purified from $E$. coli was used as positive control. Conditioned medium and cellular extract of nontransfected CHO-DXB11 cells were the negative control. Glycosylated recombinant GCR bands of $59-69 \mathrm{kDa}$ are indicated by the arrows. The volume of sample applied to the gel corresponded to the supernatant (a) or extract (b) of 150,000 cells.

TABLE 1: Expression levels of recombinant GCR secreted from the best CHO-DXB11 cell subclones.

\begin{tabular}{lc}
\hline Subclone & Productivity $(\mathrm{pg} / \mathrm{cell} / \text { day })^{*}$ \\
\hline 12.8 & 1.84 \\
12.9 & 5.14 \\
12.19 & 3.22 \\
\hline
\end{tabular}

* The productivities were calculated by comparing the GCR bands of subclones with a standard curve of non-glycosylated recombinant GCR purified from $E$. coli, in a western blotting assay followed by densitometric analysis. The experiment was conducted in triplicate. The volume of conditioned medium applied to the gel corresponded to the supernatant of 70,000 cells.

(SC 12.9) was characterized by digestion with Endo $\mathrm{H}$ and PNGase F. The western blotting (Figure 6(a)) showed a shift in the molecular mass of the protein from $66-69 \mathrm{kDa}$ to $56 \mathrm{kDa}$ after PNGase $\mathrm{F}$ digestion, which is in agreement with the expected size for nonglycosylated GCR. A $56 \mathrm{kDa}$ band was also observed for recombinant GCR purified from E. coli (positive control). In the treatment with Endo $\mathrm{H}$, GCR was partially resistant. A decrease of $\sim 3 \mathrm{kDa}$ in the $69 \mathrm{kDa}$ protein band corresponding to the loss of N-linked high-mannose-type oligosaccharide was observed, with the probable retention of complex-type oligosaccharides terminating in galactose or sialic acid, which are not digested by Endo H. No recombinant GCR bands were detected in the culture medium of nontransfected CHO-DXB11 cells (negative control). Analysis using purified commercial enzyme (Cerezyme) of $60 \mathrm{kDa}$ containing remodeled glycans (Figure 6(b)) confirmed the glycosylation status of GCR produced by $\mathrm{CHO}$ cells with a pattern of two bands 


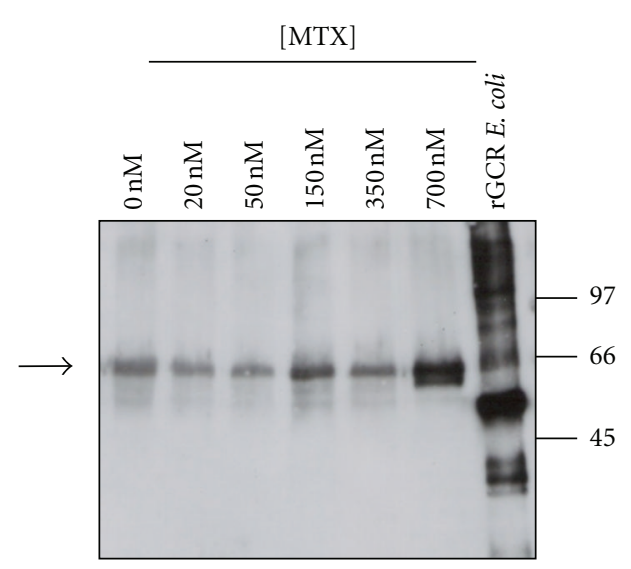

(a)

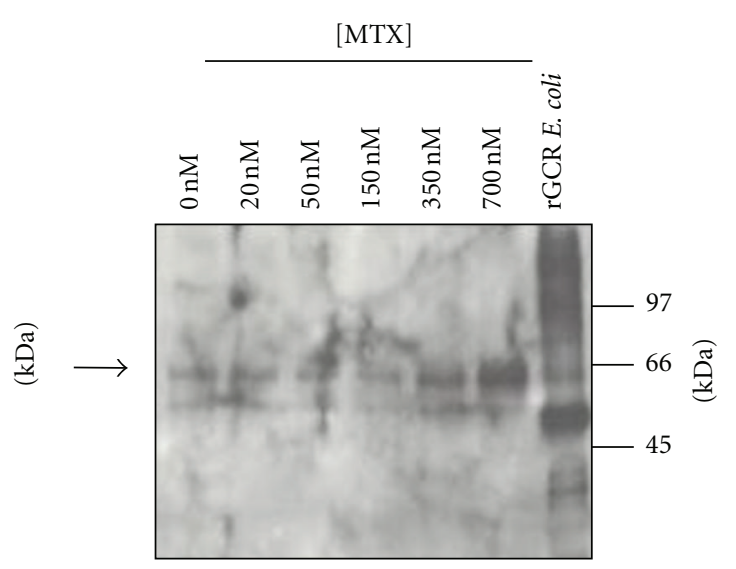

(b)

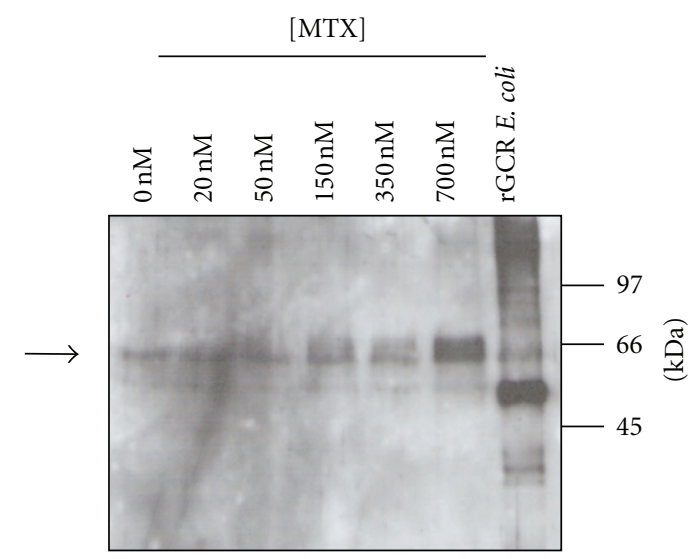

(c)

FIGURE 3: Recombinant GCR expression in conditioned media of 3 CHO-DXB11 cell clones selected throughout the stages of amplification, by western blotting analysis. (a) Clone 12, (b) clone 22, and (c) clone 37. Nonglycosylated recombinant GCR of $56 \mathrm{kDa}$ purified from E. coli was the positive control. Glycosylated recombinant GCR is indicated by arrows. The volume of culture medium applied to the gel corresponded to the supernatant of 5,000 cells.

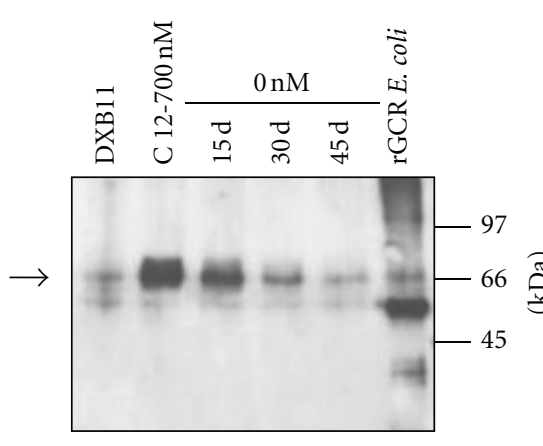

(a)

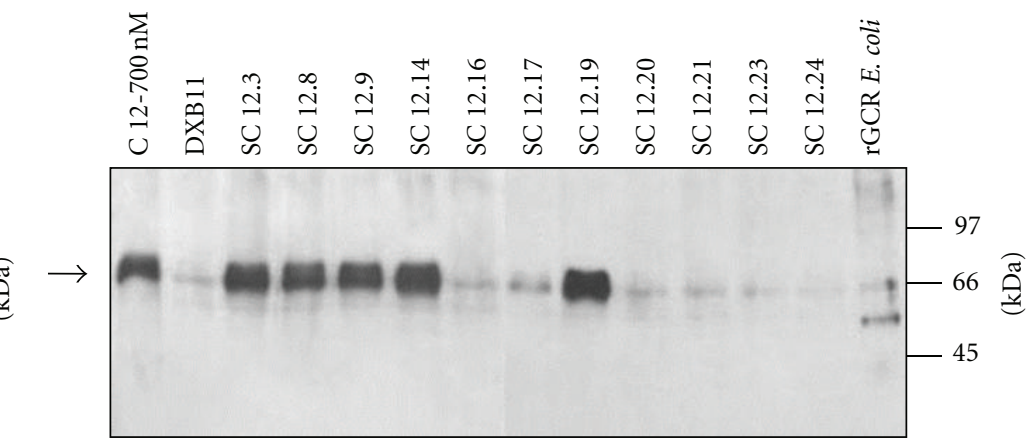

(b)

FIgURE 4: Expression of secreted GCR from transfected CHO-DXB11 cells selected at 700 nM MTX and cultivated for 45 days in MTXfree medium, by western blotting analysis. (a) Conditioned media of the high-producer clone (C 12) collected on days 15,30 , and 45 . (b) Conditioned media of 11 subclones (SC) collected on day 45. Nontransfected CHO-DXB11 cells were used as negative control. Clone 12 cultivated at $700 \mathrm{nM}$ MTX was a positive control, as well as the nonglycosylated recombinant GCR of $56 \mathrm{kDa}$ purified from E. coli. Glycosylated recombinant GCR is indicated by arrows. The volume of culture medium applied to the gel corresponded to the supernatant of 15,000 cells. 
Specific activity ( $\mu \mathrm{mol} 4-\mathrm{MU} / \mathrm{min} / \mathrm{mg})$

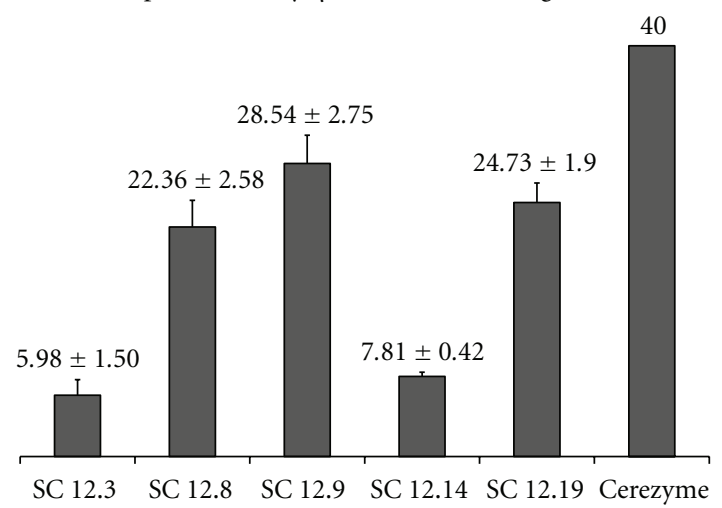

FIGURE 5: Enzymatic activity of recombinant GCR secreted from CHO-DXB11 cell subclones (SC). The reactions were carried out with the synthetic fluorogenic substrate 4-MUG. The product of enzymatic reactions 4-MU was measured at wavelength of $445 \mathrm{~nm}$ after excitation at $365 \mathrm{~nm}$. A standard curve (units per fluorescence) was constructed using specific activity data of Cerezyme. Results are specific activities obtained for subclones relative to Cerezyme, presented as means \pm SEM, measured in triplicate. The volume of conditioned medium used in this assay corresponded to the supernatant of 70,000 cells.

(66 and $69 \mathrm{kDa}$ ), as observed by endoglycosidase treatment and described elsewhere $[36,37]$.

\section{Discussion}

Although ERT has become the standard of care for type I Gaucher disease $[8,38]$, its extremely high cost prevents it from being available to many patients in several countries $[14,23-25]$. In Brazil, the drug is imported and provided by the public healthcare system free of charge and the cost for just 610 Gaucher's patients reaches the order of \$ 84 million per year (Department of Science, Technology and Strategic Inputs, personal communication, 2010), a value not comparable with the expenses to treat other priority diseases. However, the high cost of treatment could be reduced with the production of GCR by public institutions. GCR is a glycoprotein of 497 amino acids with four of the five putative $N$-glycosylation sites usually occupied [39]. The glycosylation process was proven to be essential to produce a catalytically active enzyme [39, 40]. For this reason, GCR has been produced in eukaryotic cells that have the machinery required to perform the posttranslational modifications [41-43]: Genzyme has used CHO-DG44 cells to produce imiglucerase [44], based on the dhfr amplifiable gene marker, while Shire and Protalix have developed a geneactivated expression system in a human fibroblast cell line and a plant (carrot) cell-based expression system to produce velaglucerase alfa and taliglucerase alfa $[19,21]$, respectively. In contrast to velaglucerase that have an amino acid sequence identical to that of the natural enzyme, imiglucerase, and taliglucerase contain a mutation at position 495 (an Arg to His substitution). In addition, taliglucerase sequence is modified at the $\mathrm{N}$ - and C-termini to add short tags of 2 and 7 amino acids, respectively. In this work, we describe the cloning of GCR cDNA containing the mutation R495H and the protein expression in CHO-DXB11, a cell line deficient in the DHFR synthesis, similar to CHO-DG44 cells.

The GCR cDNA was cloned into the pED dicistronic expression vector, which is commonly used to obtain highexpression levels of heterologous proteins in mammalian cells [45-47], and positive clones were isolated and amplified with increasing MTX concentration up to $700 \mathrm{nM}$ MTX. Probably due to the inability of the transfected cells to further amplify the dhfr gene [28], higher concentration of MTX (1200 nM) caused cell death. MTX selection of amplificants has been considered a major bottleneck in the production of biopharmaceuticals because many rounds are required to obtain cells with high-gene copy numbers [28, 48]. Currently, high-throughput methods to screen high-producer cells have been developed [48, 49]; including automated systems such as colony picking and the Cello systems [50]. However, many of these techniques are very expensive and nonaccessible to most undeveloped or emerging countries. In this regard, although time consuming and labor intensive, traditional methods of screening still represent an alternative for the production of recombinant glycoproteins at lower cost. Some significant problems of using traditional techniques are the relative low number of clones that can be characterized, and the need of downstream analysis of the product levels, since protein secretion cannot be measured on an individual cell basis [50].

Using traditional methods of screening for recombinant production clones, we demonstrated by immunoassays the expression of recombinant GCR either cell-associated $(\sim 64$ and $59 \mathrm{kDa})$ or secreted into the culture medium (63-69 kDa), using a murine anti-human GCR polyclonal antibody [34]. GCR has a molecular mass ranging from 59 to $69 \mathrm{kDa}$ [36], depending on the complexity of its glycan chains $[1,51]$, while the nonglycosylated GCR is a nonfunctional enzyme of $56 \mathrm{kDa}$ [39]. Thus, the molecular masses detected here for recombinant human GCR are consistent with a properly glycosylated and active enzyme. However, to use in ERT, GCR should be modified in the oligosaccharide moieties to produce mannose-terminal carbohydrates, facilitating mannose receptor-mediated uptake into macrophages [52]. GCR produced in CHO cells and commercialized by Genzyme is sequentially treated with three exoglycosidases during purification process to remove sialic acid, galactose, and $N$-acetylglucosamine residues [53, 54]. These steps have to be further included in our future production process of a therapeutically functional enzyme in CHO cells in order to obtain a biosimilar GCR.

To evaluate the stability of the producer clone, MTX was withdrawn from the culture medium and an unexpected decreased in the GCR expression was observed. Longterm culture in the absence of selective pressure may result in the loss of transgene copy number $[55,56]$, and reduction or elimination in the gene-specific transcription (gene silencing) $[49,57]$, according to the site of transgene integration. Both processes may result in the prevalence of cells expressing lower levels of the recombinant protein due to the higher growth rate presented by these cells when 


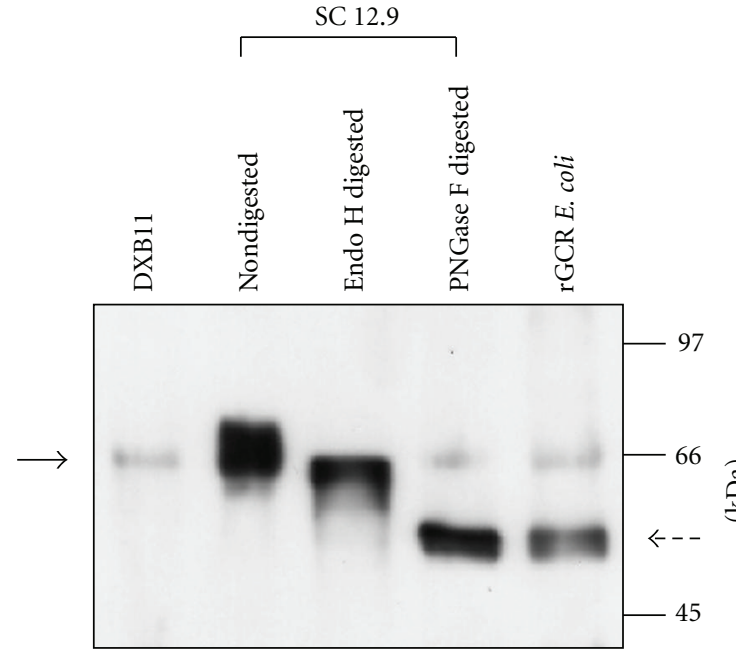

(a)

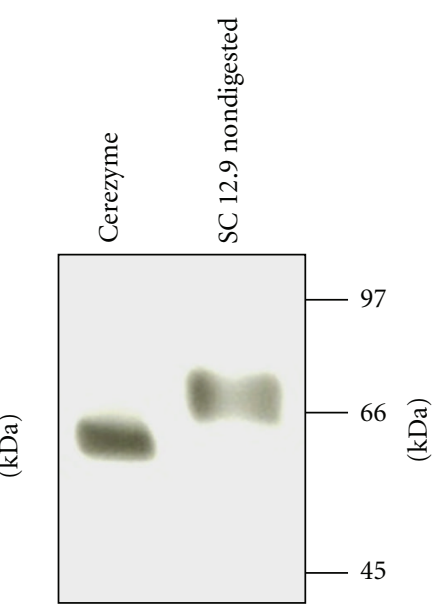

(b)

FIGURE 6: Glycosylation analysis of recombinant GCR secreted from high-producer subclone (SC 12.9) by western blotting assays. (a) Endoglycosidase digestion with Endo H and PNGase F. Samples of conditioned medium (supernatant of 150,000 cells corresponding to about $750 \mathrm{ng}$ of GCR) were precipitated with 10\% TCA previously to digestion reactions. Non-digested sample of nontransfected CHODXB11 cells was used as negative control. Nonglycosylated recombinant GCR purified from E. coli was a positive control. Glycosylated GCR bands of $66-69 \mathrm{kDa}$ and nonglycosylated GCR of $56 \mathrm{kDa}$ are indicated by solid and dashed arrows, respectively. (b) Purified commercial enzyme Cerezyme $(150 \mathrm{ng})$ of $60 \mathrm{kDa}$ containing remodeled glycosylation moieties was compared to GCR secreted from subclone 12.9 (supernatant of 30,000 cells corresponding to about $150 \mathrm{ng}$ ) with complex- and hybrid-type glycosylation pattern (66-69 kDa).

compared with the high producers [58], despite the fact that both have potentially been derived from the same single cell $[56,57]$.

Recloning was then performed in order to evaluate the heterogeneity of the producer clone, and stable subclones expressing a functional GCR with level of biological activity similar to that of Cerezyme were identified. Although the highest productivity achieved for secreted GCR was calculated as $5.14 \mathrm{pg} / \mathrm{cell} / \mathrm{day}$, higher expression levels have been reported for other recombinant proteins in $\mathrm{CHO}$ cells $[45,47]$. Here, it should be taken into account the fact that GCR is a membrane-associated glycoprotein secreted at low level or rather not secreted under natural conditions [37]. Despite the importance of the production of GCR for the treatment of ERT, there is a lack of data in the literature describing the expression of recombinant GCR in $\mathrm{CHO}$ cells. Leonova and Grabowski [37] reported the intracellular degradation and secretion processes of GCR in stably transfected CHO cells, and Genzyme's data concerning the production of imiglucerase in CHO-DG44 cells were only summarily described by Hoppe [59]. Additionally, some other information can be found in the patent files $[44,53]$. Here, we report a robust protocol for the production of recombinant GCR in $\mathrm{CHO}$ cells along with the all the steps to obtain a stable cell line expressing the enzyme.

In conclusion, we showed the generation of stable $\mathrm{CHO}$ cells producing a functional recombinant human GCR, properly glycosylated and secreted, using low-throughput methods for selection of high-producing clones. Efforts to develop a process for producing GCR by nonprofit institution may possibly result in reduced cost of treating
Gaucher disease in the future thus supplying the needs of the Brazilian public healthcare system. Furthermore, the traditional screening strategies shown here can be useful for other emerging countries to produce biopharmaceuticals and other biological products of high cost-effectiveness and public health value.

\section{Acknowledgments}

The authors are grateful to Dr. Geraldo Santana Magalhães (Laboratório de Imunopatologia, Instituto Butantan) and Dr. Eneas de Carvalho (Centro de Biotecnologia, Instituto Butantan) for helpful discussions, to Dr. Rosa Maria ChuraChambi (Centro de Biotecnologia, Instituto de Pesquisas Energéticas e Nucleares) for helping them with the transfection and gene amplification procedures, and to Dr. Henrique Roman Ramos (Centro de Biotecnologia, Instituto Butan$\operatorname{tan)}$ for assistance in the fluorometric analysis. This work was supported by grants from FAPESP (Fundação de Amparo à Pesquisa do Estado de São Paulo), CNPq (Conselho Nacional de Desenvolvimento Científico e Tecnológico), and Fundação Butantan.

\section{References}

[1] A. H. Erickson, E. I. Ginns, and J. A. Barranger, "Biosynthesis of the lysosomal enzyme glucocerebrosidase," The Journal of Biological Chemistry, vol. 260, no. 26, pp. 14319-14324, 1985.

[2] E. Beutler, "Gaucher disease: new molecular approaches to diagnosis and treatment," Science, vol. 256, no. 5058, pp. 794799, 1992. 
[3] R. O. Brady, J. N. Kanfer, and D. Shapiro, "Metabolism of glucocerebrosides II. Evidence of an enzymatic deficiency in Gaucher's disease," Biochemical and Biophysical Research Communications, vol. 18, no. 2, pp. 221-225, 1965.

[4] M. Jmoudiak and A. H. Futerman, "Gaucher disease: pathological mechanisms and modern management," British Journal of Haematology, vol. 129, no. 2, pp. 178-188, 2005.

[5] D. Elstein and A. Zimran, "Review of the safety and efficacy of imiglucerase treatment of Gaucher disease," Biologics, vol. 3, pp. 407-417, 2009.

[6] G. A. Grabowski, "Recent clinical progress in Gaucher disease," Current Opinion in Pediatrics, vol. 17, no. 4, pp. 519-524, 2005.

[7] J. A. Barranger and E. O’Rourke, "Lessons learned from the development of enzyme therapy for Gaucher disease," Journal of Inherited Metabolic Disease, vol. 24, no. 2, supplement, pp. 89-96, 2001.

[8] G. A. Grabowski, "Phenotype, diagnosis, and treatment of Gaucher's disease," The Lancet, vol. 372, no. 9645, pp. 12631271, 2008.

[9] E. Beutler, "Enzyme replacement in Gaucher disease," PLoS Medicine, vol. 1, article e21, pp. 118-121, 2004.

[10] R. O. Brady, P. G. Pentchev, and A. E. Gal, "Replacement therapy for inherited enzyme deficiency. Use of purified glucocerebrosidase in Gaucher's disease," The New England Journal of Medicine, vol. 291, no. 19, pp. 989-993, 1974.

[11] Y. Kacher, B. Brumshtein, S. Boldin-Adamsky et al., "Acid $\beta$ glucosidase: onsights from structural analysis and relevance to Gaucher disease therapy," Biological Chemistry, vol. 389, no. 11, pp. 1361-1369, 2008.

[12] K. Starzyk, S. Richards, J. Yee, S. E. Smith, and W. Kingma, "The long-term international safety experience of imiglucerase therapy for Gaucher disease," Molecular Genetics and Metabolism, vol. 90, no. 2, pp. 157-163, 2007.

[13] P. B. Deegan and T. M. Cox, "Imiglucerase in the treatment of Gaucher disease: a history and perspective," Drug Design, Development and Therapy, vol. 6, pp. 81-106, 2012.

[14] T. M. Cox, "Gaucher disease: clinical profile and therapeutic developments," Biologics, vol. 4, pp. 299-313, 2011.

[15] J. M. F. G. Aerts, U. Yasothan, and P. Kirkpatrick, "Velaglucerase alfa," Nature Reviews Drug Discovery, vol. 9, no. 11, pp. 837-838, 2010.

[16] K. Traynor, "Taliglucerase alfa approved for Gaucher disease," American Journal of Health-System Pharmacy, vol. 69, no. 12, p. 1009, 2012.

[17] B. Brumshtein, P. Salinas, B. Peterson et al., "Characterization of gene-activated human acid- $\beta$-glucosidase: crystal structure, glycan composition, and internalization into macrophages," Glycobiology, vol. 20, no. 1, pp. 24-32, 2010.

[18] J. L. Morris, "Velaglucerase alfa for the management of type 1 Gaucher disease," Clinical Therapeutics, vol. 34, pp. 259-271, 2012.

[19] A. Zimran, K. Loveday, C. Fratazzi, and D. Elstein, "A pharmacokinetic analysis of a novel enzyme replacement therapy with Gene-Activated human glucocerebrosidase (GA-GCB) in patients with type 1 Gaucher disease," Blood Cells, Molecules, and Diseases, vol. 39, no. 1, pp. 115-118, 2007.

[20] C. E. Hollak, "An evidence-based review of the potential benefits of taliglucerase alfa in the treatment of patients with Gaucher disease," Core Evidence, vol. 7, pp. 15-20, 2012.

[21] Y. Shaaltiel, D. Bartfeld, S. Hashmueli et al., "Production of glucocerebrosidase with terminal mannose glycans for enzyme replacement therapy of Gaucher's disease using a plant cell system," Plant Biotechnology Journal, vol. 5, no. 5, pp. 579-590, 2007.

[22] C. E. M. Hollak, S. vom Dahl, J. M. F. G. Aerts et al., "Force Majeure: therapeutic measures in response to restricted supply of imiglucerase (Cerezyme) for patients with Gaucher disease," Blood Cells, Molecules, and Diseases, vol. 44, no. 1, pp. 41-47, 2010.

[23] E. Beutler, "Gaucher disease as a paradigm of current issues regarding single gene mutations of humans," Proceedings of the National Academy of Sciences of the United States of America, vol. 90, no. 12, pp. 5384-5390, 1993.

[24] E. Beutler, "Lysosomal storage diseases: natural history and ethical and economic aspects," Molecular Genetics and Metabolism, vol. 88, no. 3, pp. 208-215, 2006.

[25] A. H. Futerman, J. L. Sussman, M. Horowitz, I. Silman, and A. Zimran, "New directions in the treatment of Gaucher disease," Trends in Pharmacological Sciences, vol. 25, no. 3, pp. 147-151, 2004.

[26] R. J. Kaufman, M. V. Davies, L. C. Wasley, and D. Michnick, "Improved vectors for stable expression of foreign genes in mammalian cells by use of the untranslated leader sequence from EMC virus," Nucleic Acids Research, vol. 19, no. 16, pp. 4485-4490, 1991.

[27] G. Urlaub and L. A. Chasin, "Isolation of Chinese hamster cell mutants deficient in dihydrofolate reductase activity," Proceedings of the National Academy of Sciences of the United States of America, vol. 77, no. 7, pp. 4216-4220, 1980.

[28] J. J. Cacciatore, L. A. Chasin, and E. F. Leonard, "Gene amplification and vector engineering to achieve rapid and high-level therapeutic protein production using the Dhfr-based $\mathrm{CHO}$ cell selection system," Biotechnology Advances, vol. 28, no. 6, pp. 673-681, 2010.

[29] R. J. Kaufman, "Selection and coamplification of heterologous genes in mammalian cells," Methods in Enzymology, vol. 185, pp. 537-566, 1990.

[30] K. P. Jayapal, K. F. Wlaschin, W. S. Hu, and M. G. S. Yap, "Recombinant protein therapeutics from CHO Cells-20 years and counting," Chemical Engineering Progress, vol. 103, no. 10, pp. 40-47, 2007.

[31] F. M. Wurm, "Production of recombinant protein therapeutics in cultivated mammalian cells," Nature Biotechnology, vol. 22, no. 11, pp. 1393-1398, 2004.

[32] F. Sanger, S. Nicklen, and A. R. Coulson, "DNA sequencing with chain-terminating inhibitors," Proceedings of the National Academy of Sciences of the United States of America, vol. 74, no. 12, pp. 5463-5467, 1977.

[33] F. L. Graham and A. J. van der Eb, "A new technique for the assay of infectivity of human adenovirus 5 DNA," Virology, vol. 52, no. 2, pp. 456-467, 1973.

[34] J. B. Novo, M. L. S. Oliveira, G. S. Magalhães, L. Morganti, I. Raw, and P. L. Ho, "Generation of polyclonal antibodies against recombinant human glucocerebrosidase produced in escherichia coli," Molecular Biotechnology, vol. 46, no. 3, pp. 279-286, 2010.

[35] C. M. Stoscheck, "Quantitation of protein," Methods in Enzymology, vol. 182, pp. 50-68, 1990.

[36] J. E. Bergmann and G. A. Grabowski, "Posttranslational processing of human lysosomal acid $\beta$-glucosidase: a continuum of defects in Gaucher disease type 1 and type 2 fibroblasts," American Journal of Human Genetics, vol. 44, no. 5, pp. 741750, 1989. 
[37] T. Leonova and G. A. Grabowski, "Fate and sorting of acid $\beta$-glucosidase in transgenic mammalian cells," Molecular Genetics and Metabolism, vol. 70, no. 4, pp. 281-294, 2000.

[38] M. Beck, "Therapy for lysosomal storage disorders," IUBMB Life, vol. 62, no. 1, pp. 33-40, 2010.

[39] A. Berg-Fussman, M. E. Grace, Y. Ioannou, and G. A. Grabowski, "Human acid $\beta$-glucosidase. N-glycosylation site occupancy and the effect of glycosylation on enzymatic activity," The Journal of Biological Chemistry, vol. 268, no. 20, pp. 14861-14866, 1993.

[40] M. E. Grace and G. A. Grabowski, "Human acid $\beta$-glucosidase: glycosylation is required for catalytic activity," Biochemical and Biophysical Research Communications, vol. 168, no. 2, pp. 771777, 1990.

[41] S. A. Brooks, "Appropriate glycosylation of recombinant proteins for human use: implications of choice of expression system," Applied Biochemistry and Biotechnology_Part B, vol. 28, no. 3, pp. 241-256, 2004.

[42] Y. Durocher and M. Butler, "Expression systems for therapeutic glycoprotein production," Current Opinion in Biotechnology, vol. 20, no. 6, pp. 700-707, 2009.

[43] G. Walsh, "Post-translational modifications of protein biopharmaceuticals," Drug Discovery Today, vol. 15, no. 17-18, pp. 773-780, 2010.

[44] J. Rasmussen, G. Barsomian, and M. Bergh, "Enzymatically active recombinant glucocerebrosidase," US Patent, 5, 236, 838,1993

[45] R. M. Chura-Chambi, P. H. Tornieri, P. J. Spencer, P. A. Nascimento, M. B. Mathor, and L. Morganti, "High-level synthesis of recombinant murine endostatin in Chinese hamster ovary cells," Protein Expression and Purification, vol. 35, no. 1, pp. 11-16, 2004.

[46] C. N. Peroni, C. R. J. Soares, E. Gimbo, L. Morganti, M. T. C. P. Ribela, and P. Bartolini, "High-level expression of human thyroid-stimulating hormone in Chinese hamster ovary cells by co-transfection of dicistronic expression vectors followed by a dual-marker amplification strategy," Biotechnology and Applied Biochemistry, vol. 35, no. 1, pp. 19-26, 2002.

[47] C. R. J. Soares, L. Morganti, B. Miloux, J. H. Lupker, P. Ferrara, and P. Bartolini, "High-level synthesis of human prolactin in Chinese-hamster ovary cells," Biotechnology and Applied Biochemistry, vol. 32, no. 2, pp. 127-135, 2000.

[48] D. Kuystermans, B. Krampe, H. Swiderek, and M. Al-Rubeai, "Using cell engineering and omic tools for the improvement of cell culture processes," Cytotechnology, vol. 53, no. 1-3, pp. 3-22, 2007.

[49] D. L. Hacker, M. De Jesus, and F. M. Wurm, "25 years of recombinant proteins from reactor-grown cells-where do we go from here?" Biotechnology Advances, vol. 27, no. 6, pp. 1023-1027, 2009.

[50] S. M. Browne and M. Al-Rubeai, "Selection methods for highproducing mammalian cell lines," Trends in Biotechnology, vol. 25, no. 9, pp. 425-432, 2007.

[51] S. Takasaki, G. J. Murray, and F. S. Furbish, "Structure of the $\mathrm{N}$-asparagine-linked oligosaccharide units of human placental $\beta$-glucocerebrosidase," The Journal of Biological Chemistry, vol. 259, no. 16, pp. 10112-10117, 1984.

[52] S. M. Van Patten, H. Hughes, M. R. Huff et al., "Effect of mannose chain length on targeting of glucocerebrosidase for enzyme replacement therapy of Gaucher disease," Glycobiology, vol. 17, no. 5, pp. 467-478, 2007.

[53] B. Friedman and M. Hayes, "Enhanced in vivo uptake of glucocerebrosidase,” US Patent, 5, 549, 892, 1996.
[54] F. S. Furbish, C. J. Steer, N. L. Krett, and J. A. Barranger, "Uptake and distribution of placental glucocerebrosidase in rat hepatic cells and effects of sequential deglycosylation," Biochimica et Biophysica Acta, vol. 673, no. 4, pp. 425-434, 1981.

[55] C. H. Fann, F. Guirgis, G. Chen, M. S. Lao, and J. M. Piret, "Limitations to the amplification and stability of human tissue-type plasminogen activator expression by Chinese hamster ovary cells," Biotechnology and Bioengineering, vol. 69, no. 2, pp. 204-212, 2000.

[56] N. S. Kim, S. J. Kim, and G. M. Lee, "Clonal variability within dihydrofolate reductase-mediated gene amplified Chinese hamster ovary cells: stability in the absence of selective pressure," Biotechnology and Bioengineering, vol. 60, pp. 679-688, 1998.

[57] J. Chusainow, Y. S. Yang, J. H. M. Yeo et al., "A study of monoclonal antibody-producing $\mathrm{CHO}$ cell lines: what makes a stable high producer?" Biotechnology and Bioengineering, vol. 102, no. 4, pp. 1182-1196, 2009.

[58] M. B. Gu, J. A. Kern, P. Todd, and D. S. Kompala, "Effect of amplification of dhfr and lac $\mathrm{Z}$ genes on growth and $\beta$-galactosidase expression in suspension cultures of recombinant CHO cells," Cytotechnology, vol. 9, no. 1-3, pp. 237-245, 1992.

[59] H. Hoppe, "Cerezyme-recombinant protein treatment for Gaucher's disease," Journal of Biotechnology, vol. 76, no. 2-3, pp. 259-261, 2000. 

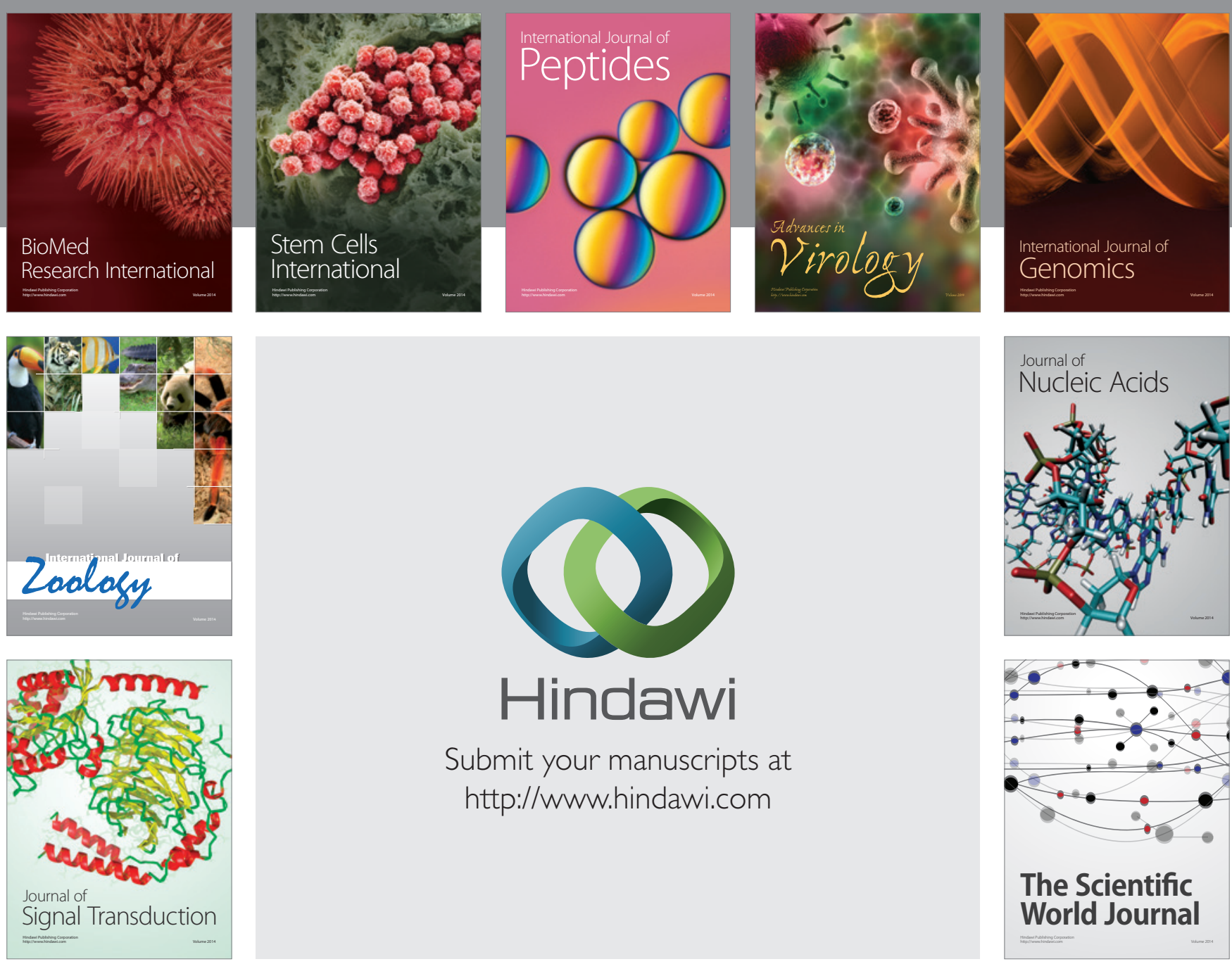

Submit your manuscripts at

http://www.hindawi.com
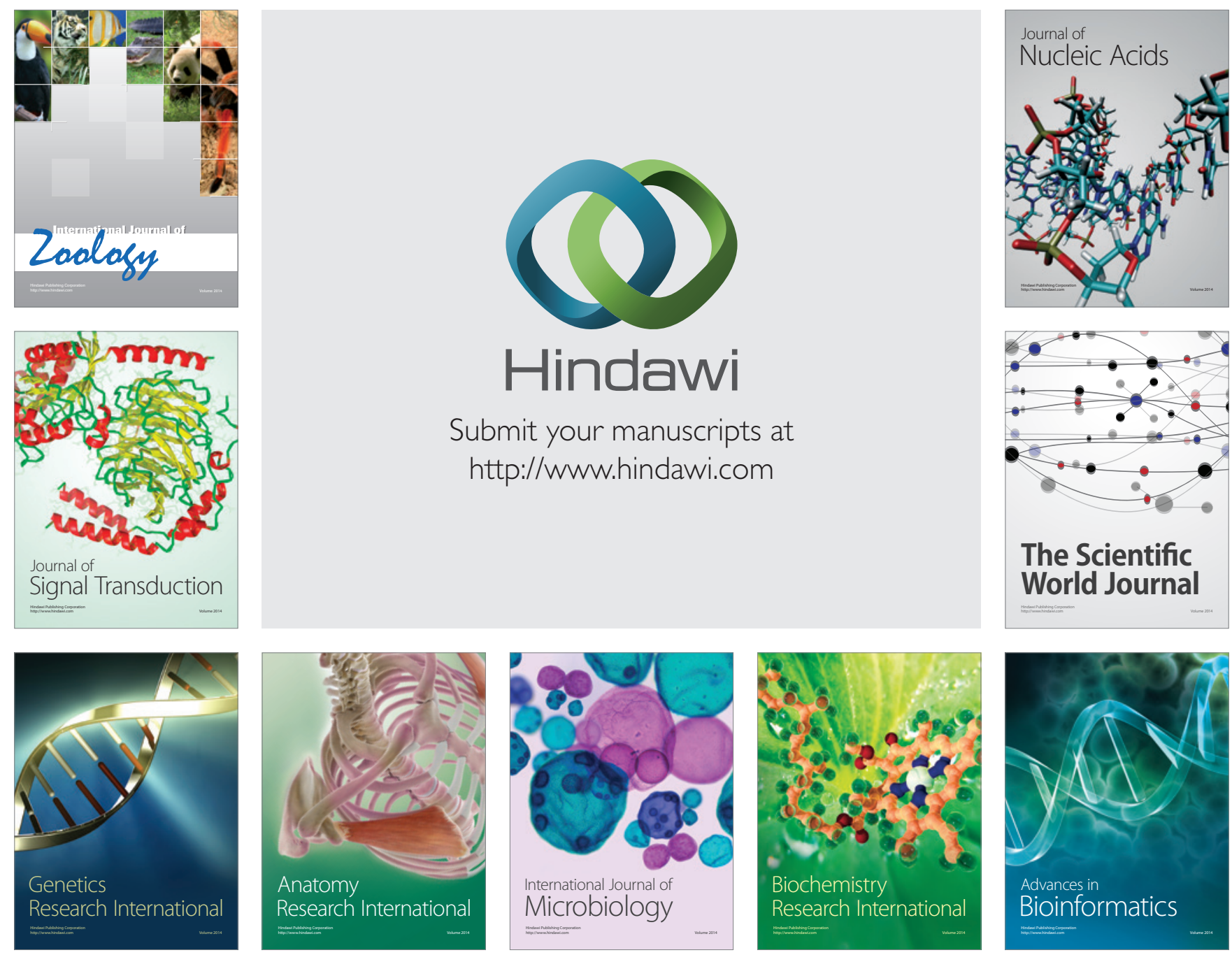

The Scientific World Journal
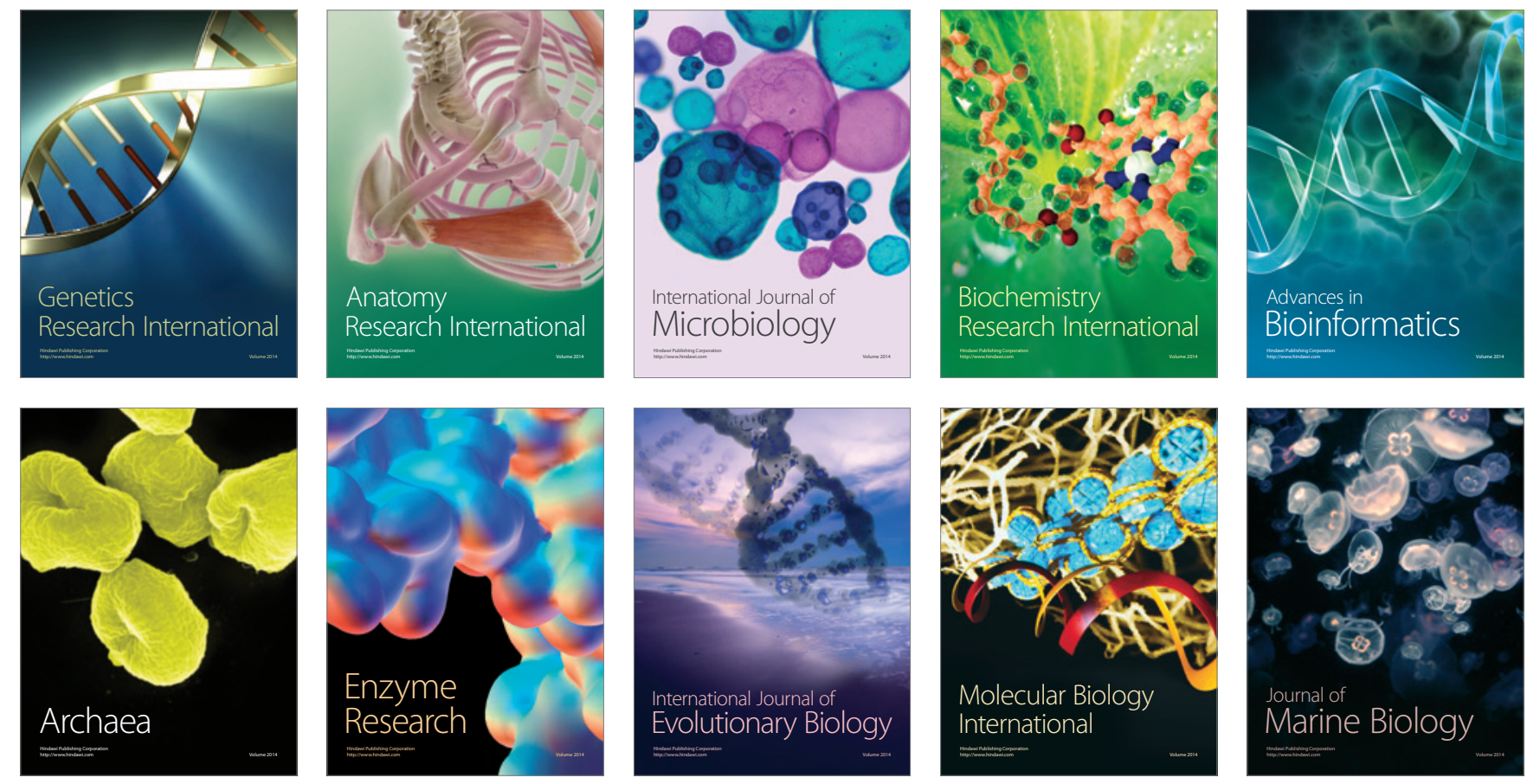